\title{
COVID-19 Lockdown: Challenges Faced by Indian Students
}

\author{
${\text { Gurjant } \operatorname{Singh}^{1} \text { (D) Shana Quraishi }}^{1}$
}

Received: 7 July 2020/Accepted: 1 June 2021 / Published online: 20 July 2021

(C) National Academy of Psychology (NAOP) India 2021

\begin{abstract}
Fear of spread of the COVID-19, disciplinary lockdown, and delay in getting back to the normal routine of education centers is affecting the academic performance of the students, as they are facing difficulties to cope up with the new mode of learning. The purpose of this study was to look out for the challenges faced in learning during the lockdown and if they were raising the mental stress in students. A self-structured questionnaire including 10 questions formed through Google forms and validated using online Delphi method was forwarded to the students from different colleges and universities of Haryana and Punjab regions of North India. Out of a total of 844 student participants, 631 (74.8\%) students were facing difficulty in studies. Whereas 744 (88.2\%) students felt that they may encounter the loss of studies during the lockdown. The study found that most of the students are facing difficulties in the study during the lockdown which is increasing the mental stress.
\end{abstract}

Keywords Coronavirus · COVID-19 - Pandemics · Students · Virus diseases

Gurjant Singh

singh.gurjant@mmumullana.org

Shana Quraishi

sana13quraishi@gmail.com

1 Maharishi Markandeshwar Institute of Physiotherapy and Rehabilitation, Maharishi Markandeshwar University, Mullana, Ambala, Haryana 133207, India

\section{Introduction}

A feeling of melancholy has evolved all across the globe from a newly emerging infectious disease whose journey is said to be started from Wuhan, China in December 2019 which is being referred to as coronavirus or COVID-19 and is now rapidly affecting the whole world (Kannan et al., 2020; Esakandari et al., 2020). Also, COVID-19 is being considered as a major source of disaster in the twenty-first century. And the sad part is that currently there are no specific vaccine or antiviral drugs that can be used for the treatment purpose (Esposito et al., 2020).

This whole scenario has been reported to leave an inauspicious psychological impact on the children, the general public, older adults as well as on the patients and medical staff (Singh, 2020; Yang et al., 2020). Amidst COVID-19 threat, the Indian government announced a nationwide lockdown on 24th March 2020, to tackle and control the spread of the virus in the country (Esposito et al., 2020; Barkur et al., 2020). Lockdown was a much required and an important step at the time, but it has challenged the normal living, work, economy, and most importantly the education of students due to closure of all the colleges and universities (Brooks et al., 2020). Even after the lockdown, there is uncertainty over the future scenario of studies as there is no specific cure and vaccine for COVID-19 to date. To prevent the shortfall in syllabus completion, the educational institutes made up the decision of starting online classes with regulations of Indian Government and University Grants Commissions (UGC). But, learning being a practical process is known best to work out when interacted with other learners (Ammenwerth \& Hackl, 2017). Also, the disappointment in Indian teachers has been reported as they are now burdened with additional academic and non-academic duties 
(Ritesh et al., 2020). This in turn can put the teachers' morale down and studies have proved how it can put adverse effects on the learning process of students (Mackenzie, 2007).

Online learning can be a challenge because of the spatial and temporal distribution of students (Endler et al., 2012). Therefore, the screening of the extent of challenges on learning in students was much required, as if left unaddressed, it may lead to stress, anxiety, and some serious mental health issues (Singh, 2020; Majumdar et al., 2020). There is still a lack of proper vaccine and treatment against COVID-19, and online learning requires to be adapted for a long time. Also, in future, similar illness could be encountered and there is a need to adapt the culture of online learning by the Indian students. Also, there is a requirement of adapting to science and technology for future encounters like this (Ali \& Alharbi, 2020). So, to make it efficient, challenges encountered during such measures must be traced and addressed. This study might be helpful in providing attention to the hidden but emerging challenges for the students which requires a positive and practical approach to save the future of the country from some worst mental health issues.

\section{Methods}

\section{Ethical Statement}

The internet-based E-survey was not submitted for approval by the Institutional Ethics Committee (IEC) due to complete lockdown in the country. But, it was ensured that the study was performed according to the principles of Helsinki declaration (revised 2013) and has followed the National Ethical Guidelines for Biomedical and Health Research involving Human Subjects-ICMR guidelines (revised 2017).

\section{Sample Size Estimation and Recruitment}

The required sample size for this cross-sectional study was estimated using the formula for estimating proportion: $n=\mathrm{Z} \alpha 2 \mathrm{P}(1-P) / \mathrm{d} 2$, where $\mathrm{Z} \alpha=1.96 ; P=90 \%$ as the response rate of the online survey, and $d=5 \%$. The minimum sample size for this study was estimated to be 139 . The survey period was kept for a time window of two weeks ensuring participation of minimum estimated participants. The inclusion criteria for the participants included the undergraduate and postgraduate students, belonging to the private universities providing online classes and the students capable of understanding the English language. The students who were not involved with the online lectures were excluded from the participation in the study.

\section{Study Procedure}

A cross-sectional survey was conducted using a selfstructured questionnaire designed with 10 Dichotomous questions through Google Forms platform to explore the difficulties in learning being faced by the students during the COVID-19 lockdown. The survey was carried out in the English language. Participants' response to the invitation was considered to imply consent. The survey was conducted among college-going undergraduate and postgraduate students from the various regions of Haryana and Punjab, in India. A total of 844 students participated in this survey voluntarily. Questionnaire content validation was performed by the experts in teaching, using an online Delphi method. The questionnaire was shared using a link, (https://forms.gle/PEr5ga5D5pu8wsBk7) through Email, Facebook, and Whatsapp. The online survey method was chosen as being an inexpensive, time-saving, and achievable without much effort during the lockdown. Students were initially asked to provide data on demographics (name, age, and gender) followed by the questions on the possible physical, social, and mental factors that were supposed to affect studies.

\section{Results}

Over the period of two weeks, 844 college-going students within the age group of 18-30 years participated in this study, of which 587 students were female and 257 students were male (Fig. 1). Out of the total 844 students, $84.1 \%$ of students were Undergraduate students, while $15.9 \%$ were

\section{Total Students $=844$}

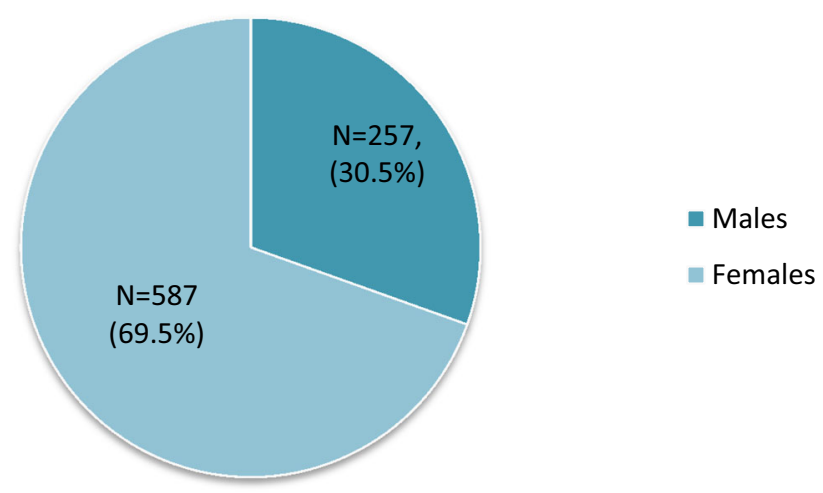

Fig. 1 Number of male and female participants in the study 
Postgraduate students. $74.8 \%$ of student participants' felt difficulty in learning during the lockdown. $85.1 \%$ of students reported that their college/institute offers online classes daily and $84.6 \%$ of students attend classes on their own initiative and $15.4 \%$ of students attend classes for the sole purpose of attendance. Just $68.7 \%$ of students were able to understand the lecture given via online teaching and $78 \%$ of students suggested the accessibility problems of the network as the reason for online learning difficulties. The home environmental element has mixed reactions with $51.7 \%$ of students accepting that the homely environment influences the study concentration while the remaining $48.3 \%$ disagreed.

There was a lack of enthusiasm for online classes in $71.2 \%$ of students and $70 \%$ of students felt adequately motivated to pursue online outlets for study on their own. Of the total participants, $75.6 \%$ of students thought that their intellectual learning is often impaired by a lack of physical activity. $88.2 \%$ of students registered to fear of loss of studies during the whole lockdown scenario. Graphical representation of results to respective questions of survey form has been given in Figs. 1 and 2. (Fig. 3)

\section{Discussion}

The present study was conducted to know the magnitude of various factors which were thought to pose a challenge amongst students to align with their studies during COVID-
19 lockdown. The questionnaire proceeded by discussing numerous factors that may challenge the learning process during the lockdown period, such as regularity of online classes, ability to attend classes, online lecture comprehension, internet access, home setting, excitement, and motivation. The report also discussed the concern about the lack of physical activity, which can adversely affect mental learning.

Since online classes were not commonly practiced in India as mainstream teaching methods, it was important to introduce such a method suddenly during an emergency to avoid the loss of education, but it also brought a number of challenges for students to adapt to this learning mode. Nearly $75 \%$ of the students said they have problems learning during the lockdown, this could be due to the homely atmosphere and the lack of physical activities that make the routine lazier. But, almost half of the students disagreed with the belief that their learning is affected by home climate. Thus, there is a need to take into consideration the other factors that may cause difficulties. This study found that $31.3 \%$ of students are unable to understand the online lectures given. Different reasons may be responsible for this, with low Internet connectivity being the primary one in some regions of India. Moreover, the one-to-one interaction between learner and instructor is not that successful with the online classes, that too might be one of the reasons for a lesser understanding of the lecture. It has been found that most of the students were encountering lack of enthusiasm in studies and a few students felt
Fig. 2 Participants' response to Q1-Q5

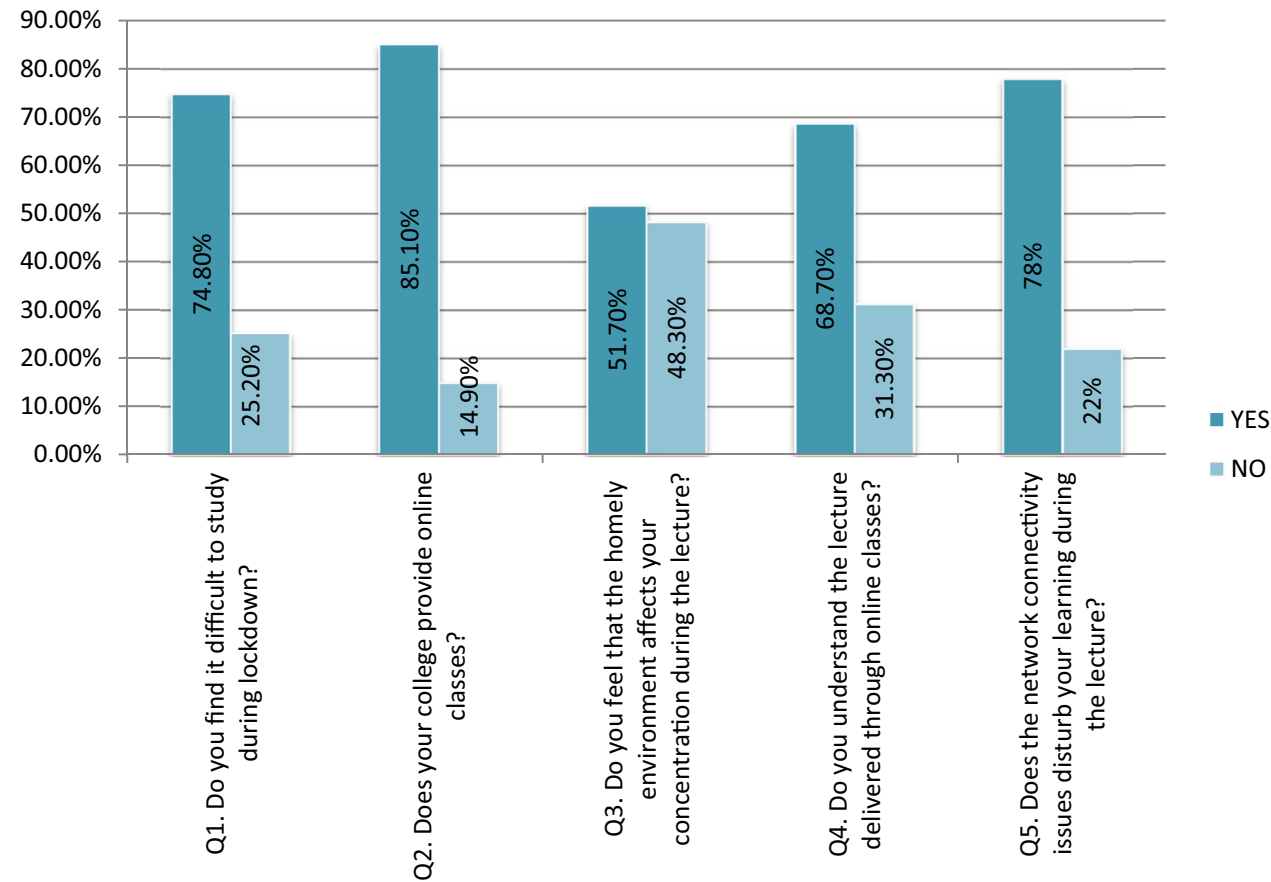


Fig. 3 Participants' response to Q6-Q10

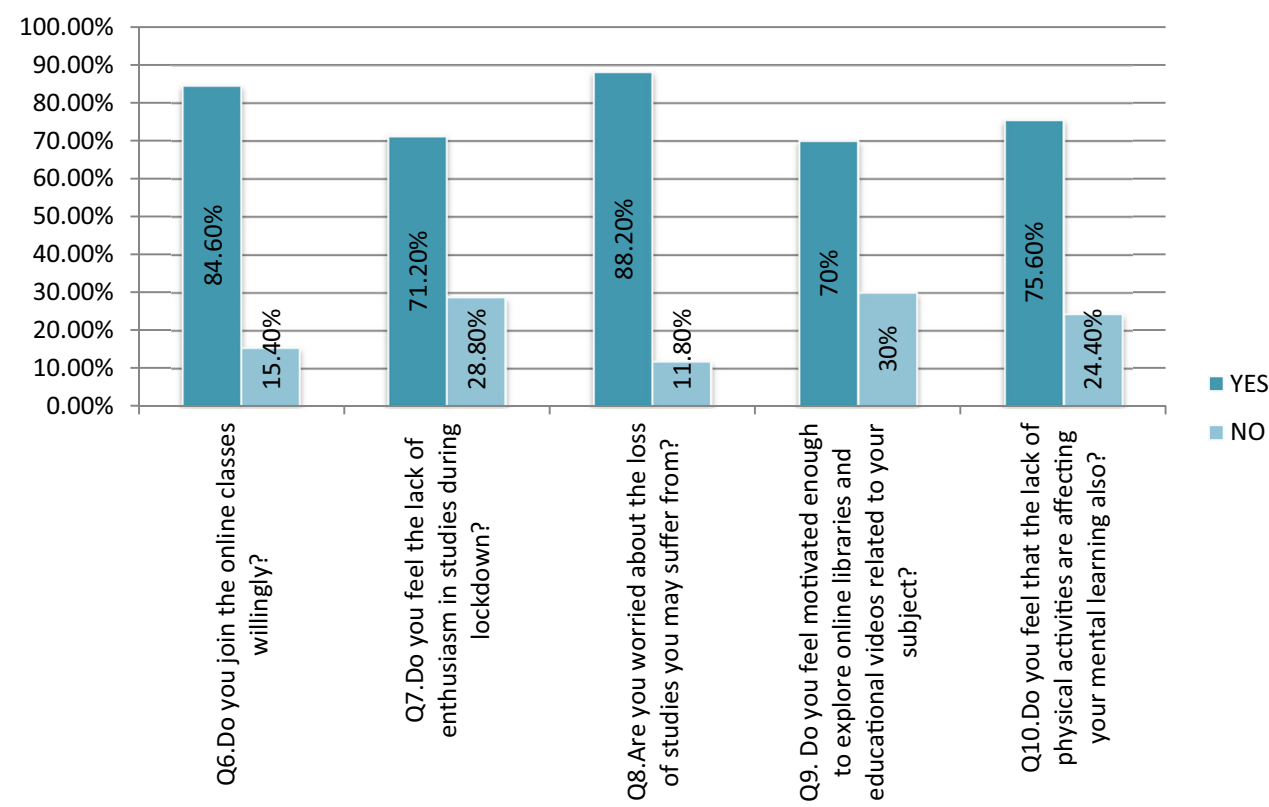

lack of inspiration to acquire additional steps for acquiring information by investigating the online instruction assets. As the college environment has been aggravated, students do not go through the subjective things in his/her daily activities which is breaking their subjective orientation. Along with these, expanded utilization of social media applications moreover seems to be the reason for the deviation of intellect from studies.

The foremost vital finding of this study was the state of concern. Amongst the total number of student participants, $88.2 \%$ were found to be stressed about the misfortune of considers they may endure due to the lockdown and result came out justified with findings of a recent study which states that the mental wellbeing of college students is altogether influenced when confronted with well-being crises, and they require consideration, assistance, and bolster of the society, families, and colleges. It is proposed that the government and colleges/institutes ought to collaborate to resolve this issue by supplying high-quality, convenient, and crisis-oriented mental administration to the students (Cao et al., 2020). Also, a study done recently portrays one worsening of the psychiatric condition of an individual after the approach of COVID-19, study claims that numerous such cases could be seen in the immediate future (Ajay \& Aditya, 2020). This requires a genuine consideration, as the worry may not only create mental stress and pressure but may also cause other genuine wellbeing issues such as uneasiness, misery, motivation to hurt themselves and to maintain a strategic distance from confronting the disappointment.

\section{Conclusion}

The study concluded that the students are facing challenges to study during the lockdown which is causing the development of mental stress due to uncertainity over the studies and completion of syllabus along with the understanding of subjects. This stress itself may lead to increased panic forcing the students to take unhealthy and harsh decisions to avoid disappointment or failure. Also, the study concluded that lesser physical activities are affecting the mental learning of students.

\section{Data and Material Availability}

Data are available from the authors with the permission of Google Forms.

Acknowledgements The authors are very thankful to Dr. Adarsh Kumar Srivastav (PT), University Research Fellow, and Dr. Saumya Kothiyal (PT), Assistant Professor of Maharishi Markandeshwar Institute of Physiotherapy and Rehabilitation, Maharishi Markandeshwar (Deemed to be University), Mullana, India for their assistance during the development of this manuscript. The authors also thank all the participating students for their time and inputs, without whom this survey would not have been accomplished.

Author's Contributions GS, SQ conceived and designed the study, conducted research, provided research materials, collected and organized data. GS wrote initial draft of article. SQ provided the logistic support. All the authors approved the final draft of article. 
Funding This research received no specific grant from any funding agency in the public, commercial, or not-for-profit sectors.

\section{Declarations}

Conflicts of interest No potential conflicts of interest with respect to the research, authorship, and/or publication of this article.

Ethics Approval The study was approved by the Institutional Ethics Committee of Maharishi Markandeshwar (Deemed to be University), Mullana-Ambala, Haryana, India.

Consent to Participate Attempting the survey questionnaire was considered as providing consent for participants in their study.

\section{References}

Ajay, K., \& Aditya, S. (2020). Dealing with corona virus anxiety and OCD. Asian J. Psychiatry. https://doi.org/10.1016/j.ajp.2020.102 053

Ali, I., \& Alharbi, O. M. L. (2020). COVID-19: Disease, management, treatment, and social impact. Science of the Total Environment, 728, 1-6.

Ammenwerth, E., \& Hackl, W. O. (2017). Monitoring of students' interaction in online learning settings by structural network analysis and indicators. Stud Health Technol Inform, 235, 293-297. https://doi.org/10.3233/978-1-61499-753-5-293

Barkur, G., \& Vibha, K. G. (2020). Sentiment analysis of nationwide lockdown due to COVID 19 outbreak: Evidence from India. Asian J Psychiatry. https://doi.org/10.1016/j.ajp.2020.102089

Brooks, S. K., Webster, R. K., Smith, L. E., Woodland, L., Wessely, S., Greenberg, N., \& Rubin, G. J. (2020). The psychological impact of quarantine and how to reduce it: Rapid review of the evidence. The Lancet, 395(10227), 912-920. https://doi.org/10.1 016/S0140-6736(20)30460-8

Cao, W., Fang, Z., Hou, G., Han, M., Xu, X., Dong, J., \& Zheng, J. (2020). The psychological impact of the COVID-19 epidemic on college students in China. Psychiatry Research, 287, 112934. https://doi.org/10.1016/j.psychres.2020.112934

Endler, A., Rey, G. D., \& Butz, M. V. (2012). Towards motivationbased adaptation of difficulty in e-learning programs. Australasian Journal of Educational Technology, 28(7), 1119-1135.

Esakandari, H., Nabi-afjadi, M., Fakkari-afjadi, J., Farahmandian, N., Miresmaeili, S., \& Bahreini, E. (2020). A comprehensive review of COVID-19 characteristics. Biol Proced Online, 22(19), 1-10.

Esposito, S., Noviello, S., \& Pagliano, P. (2020). Update on treatment of covid-19: Ongoing studies between promising and disappointing results. Infezioni in Medicina, 28(2), 198-211.

Kannan, S., Ali, P. S. S., Sheeza, A., \& Hemalatha, K. (2020). COVID-19 (Novel Coronavirus 2019)—recent trends. European Review for Medical and Pharmacological Sciences, 24, 2006-2011. https://doi.org/10.1111/j.1467-6346.2020.09549.x

Mackenzie, N. (2007). Teacher morale: More complex than we think? Australian Educational Researcher, 34(1), 89-104. https://doi.org/10.1007/BF03216852

Majumdar, P., Biswas, A., \& Sahu, S. (2020). COVID-19 pandemic and lockdown: Cause of sleep disruption, depression, somatic pain, and increased screen exposure of office workers and students of India. Chronobiol Intl. https://doi.org/10.10 80/07420528.2020.1786107

Ritesh, B., Varun, S. K., Nithesh, N., \& Mulimani Prashant, K. N. (2020). COVID 2019 outbreak: The disappointment in Indian teachers. Asian J Psychiatry. https://doi.org/10.1016/j.ajp.2020.10 2047

Singh, G. (2020). Unstable education system inducing mental stress in COVID-19 lockdown. Open Access Maced J Med Sci, 8(T1), 248-249. https://doi.org/10.3889/oamjms.2020.5093

Yang, Y., Li, W., Zhang, Q., Zhang, L., Cheung, T., \& Xiang, Y. T. (2020). Mental health services for older adults in China during the COVID-19 outbreak. The Lancet Psychiatry, 7(4), e19. https://doi.org/10.1016/S2215-0366(20)30079-1

Publisher's Note Springer Nature remains neutral with regard to jurisdictional claims in published maps and institutional affiliations. 